\title{
H. influenzae potentiates airway epithelial cell responses to rhinovirus by increasing ICAM-1 and TLR3 expression
}

\author{
Umadevi S. Sajjan,* Yue Jia,* Dawn C. Newcomb, ${ }^{\dagger}$ J. Kelley Bentley,* \\ Nicholas W. Lukacs, ${ }^{\ddagger}$ John J. LiPuma, ${ }^{*}$ and Marc B. Hershenson ${ }^{*},{ }^{\dagger},{ }^{\prime}$ \\ *Department of Pediatrics and Communicable Diseases, ${ }^{\dagger}$ Department of Molecular and Integrative \\ Physiology, and ${ }^{\ddagger}$ Department of Pathology, University of Michigan, Ann Arbor, Michigan, USA
}

ABSTRACT Rhinovirus (RV) is an important trigger of chronic obstructive pulmonary disease (COPD) exacerbations. In addition, respiratory viruses are more likely to be isolated in patients with a history of frequent exacerbations, suggesting that these patients are more susceptible to viral infection. To examine potential mechanisms for cooperative effects between bacterial and viral infection in COPD, we studied the responses of cultured human airway epithelial cells to nontypeable Hemophilus influenzae and RV. In both 16HBE14o- and primary mucociliary-differentiated cells, preincubation with $H$. influenzae enhanced RV serotype 39-induced protein expression of interleukin (IL)-8, epithelial-derived neutrophil attractant-78, and growth-related oncogene- $\alpha$. H. influenzae infection also increased the binding of RV39 to cultured cells, as well as expression of intercellular adhesion molecule (ICAM)-1 and Toll-like receptor (TLR)-3, receptors for RV and dsRNA, respectively. Neutralizing antibody against tumor necrosis factor- $\alpha$ inhibited IL-8 expression induced by $H$. influenzae and RV39. Finally, siRNA against TLR3 attenuated RV-induced IL-8 expression. We conclude that $\boldsymbol{H}$. influenzae infection increases airway epithelial cell ICAM-1 and TLR3 expression, leading to enhanced binding of RV and a potentiation of $\mathrm{RV}$-induced chemokine release. These data provide a cellular mechanism by which $\boldsymbol{H}$. influenzae infection may increase the susceptibility of COPD patients to RVinduced exacerbations.-Sajjan, U. S., Jia, Y., Newcomb, D. C., Bentley, J. K., Lukacs, N. W., LiPuma, J. J., Hershenson, M. B. H. influenzae potentiates airway epithelial cell responses to rhinovirus by increasing ICAM-1 and TLR3 expression FASEB J. 20, E1419-E1429 (2006)

Key Words: chronic obstructive pulmonary disease $\cdot I L-8 \cdot e p$ ithelial-derived neutrophil attractant-78 $\cdot$ growth-related oncogene- $\alpha \cdot$ chemokine

Chronic obstructive pulmonary disease (COPD), is a chronic progressive disease with intermittent acute exacerbations associated with viral and/or bacterial infections. Nontypeable $H$. influenzae has been isolated from airways of clinically stable COPD patients (1-3), suggesting that it can cause chronic infection. Exacerbations of COPD have been associated with intracellular nontypeable Hemophilus influenzae (4) and acquisition of new strains of $H$. influenzae, Moraxella catarrhalis, Streptococcus pneumoniae (5), and, in patients with severely reduced lung function, Enterobacter and Pseudomonas species (6). Thus, it has been estimated that bacterial infection is responsible for about half of COPD exacerbations (7).

Rhinovirus (RV), a single-stranded RNA virus that is responsible for most of the common colds, is also important trigger of acute exacerbations in COPD patients. Between $27-56 \%$ of COPD exacerbations are associated with respiratory viral infections, and $\mathrm{RV}$ is the most common virus isolated $(8-10)$. Although RV has not been cultured from the lower airways (11), it is found in bronchial epithelial cells after infection of human volunteers $(12,13)$. In COPD exacerbations, RV is recovered from sputum more often than from nasal aspirates, consistent with the idea that RV can infect lower airways and contribute to inflammatory changes (14). Respiratory viruses are more likely to be isolated in patients with a history of frequent COPD exacerbations (9), suggesting that patients with frequent exacerbations are more susceptible to viral infection (15).

Neutrophil number and the chemokines interleukin (IL)-8 and epithelial-derived neutrophil attractant (ENA)-78 (also known as CXCL5) are increased in the sputum and airways of patients with COPD exacerbations (16-20). IL-8 and ENA-78 are C-X-C chemokines that contain the neutrophil-activating glutamic acidleucine-arginine (ELR) amino acid motif. Thus, RV may stimulate COPD exacerbations by inducing bronchial epithelial cell production of IL-8 and ENA-78, leading to an exaggerated neutrophilic inflammatory response.

Expression of intercellular adhesion molecule (ICAM)-1, the receptor for major subtype RV, is in-

\footnotetext{
${ }^{1}$ Correspondence: University of Michigan, 1150 W. Medical Center Dr., Rm. 3570, MSRBII, Box 0688, Ann Arbor, MI 48109-0688, USA. E-mail: mhershen@umich.edu

doi: 10.1096/fj.06-5806fje
} 
creased in the airway epithelium of patients with chronic bronchitis and airway obstruction (21), and $H$. influenzae stimulates ICAM-1 expression on respiratory epithelial cells (22), suggesting a mechanism for additive or synergistic effects between bacterial and viral infection. Nevertheless, little information exists regarding potential interactions between viruses and bacteria in the pathogenesis of COPD exacerbations. For example, the effects of prior bacterial infection on binding of RV to airway epithelial cells, or on RV-induced responses, have not been studied.

In the present study, we investigated the cooperative effects of $H$. influenzae and RV on ELR(+) C-X-C chemokine production from airway epithelial cells. We hypothesized that $H$. influenzae infection increases expression of airway epithelial cell ICAM-1 and Toll-like receptor (TLR)-3, leading to increased RV binding and exaggerated RV-induced chemokine responses.

\section{MATERIALS AND METHODS}

\section{Cell culture}

Human primary airway epithelial cells obtained from the tracheal trimmings of donor lungs at the time of double lung transplantation were cultured in collagen-coated plates using bronchial epithelial cell culture media (BEGM; Cambrex Bioscience, Walkersville, MD), as described previously (23). Cells were stored in liquid nitrogen until required. To obtain airway epithelial cells differentiated into mucociliary phenotype, epithelial cells frozen at passage one were seeded on collagencoated transwells and grown under submerged conditions in BEGM until the cells were confluent. The cells were shifted to air/liquid interface and maintained in 1:1 mixture of BEGM and Dulbecco's modified Eagle's medium (DMEM) for $2 \mathrm{wk}$.

16HBE14o- human bronchial epithelial cells originating from bronchial epithelial tissue transfected with pSVori-, containing the origin-defective SV40 genome (24), were provided by Dr. Steven White (University of Chicago). Cells were grown in minimum essential medium supplemented with $10 \% \mathrm{FBS}$ and $2 \mathrm{mM}$ of L-glutamine. Human epithelial kidney (HEK) 293 cells with stable TLR3 expression and vector control cells were and propagated in DMEM containing $2 \mathrm{mM}$ L-glutamine, $10 \% \mathrm{FBS}$, and $530 \mu \mathrm{g} / \mathrm{ml} \mathrm{G418.}$

\section{Bacteria and growth conditions}

H. influenzae strain 12, a well-characterized nontypeable clinical strain originally isolated from a middle ear infection (25), was kindly provided by Dr. Graham Krasan (University of Michigan). H. influenzae was maintained as a glycerol stock at $-80^{\circ} \mathrm{C}$, subcultured on blood agar plates, and incubated overnight at $37^{\circ} \mathrm{C} / 5 \% \mathrm{CO}_{2}$. Bacteria were scrapped off of the plate and suspended in cell culture medium devoid of serum and antibiotics to the required concentration. In selected experiments, bacteria were incubated at $80^{\circ} \mathrm{C}$ for $30 \mathrm{~min}$ with occasional mixing. This treatment killed $100 \%$ of the bacteria, as determined by dilution plating.

\section{Rhinovirus}

RV serotype 39 (RV39) was obtained from American Type Culture Collection (Manassas, VA). Viral stocks were generated by infecting HeLa cells with RV until $80 \%$ of the cells were cytopathic. Hela cell lysates or supernatants were harvested, and cellular debris was pelleted by centrifugation $\left(10,000 \mathrm{~g}\right.$ for $30 \mathrm{~min}$ at $\left.4^{\circ} \mathrm{C}\right)$. RV was concentrated and partially purified by centrifugation with a 100,000 molecular weight cutoff Centricon filter $\left(2,000 \mathrm{rpm}\right.$ at $4^{\circ} \mathrm{C}$ for $8 \mathrm{~h}$; Millipore, Billerica, MA; ref 26). TCID $_{50}$ values of viral stocks were determined by the Spearman-Karber method (27). Similarly treated HeLa cell lysates from mock-infected cells served as controls (sham media controls). To generate ${ }^{35} \mathrm{~S}-$ labeled RV39, HeLa cells were shifted to methionine and cysteine-free DMEM containing ${ }^{35}$ S-labeled cysteine and methionine, infected with RV39 as before, and incubated for $48 \mathrm{~h}$. Culture supernatant was collected, clarified by centrifugation, concentrated by ultrafiltration, and finally precipitated with $6 \%$ polyethylene glycol overnight. Precipitatecontaining virus was dissolved in $0.5 \mathrm{ml}$ sterile PBS.

\section{Infection of cell cultures}

All cell cultures were shifted to serum- and antibiotic-free medium at least $18 \mathrm{~h}$ before infection with $H$. influenzae. For cultures grown at air/liquid interface, the apical surface of the cultures was infected with $50 \mu \mathrm{l}$ PBS or PBS containing $1 \times 10^{5}$ or $1 \times 10^{6}$ colony-forming units of $H$. influenzae and incubated for $8 \mathrm{~h}$. The apical surface was then washed, the medium in the basolateral chamber was replaced, and the apical surface was infected with $50 \mu \mathrm{l}$ RV39, multiplicity of infection (MOI) of $0.5,1$, or 5 , or sham-infected media controls. After a $2 \mathrm{~h}$ incubation period, medium from apical surface was removed, and the cells were further incubated for 24 or $48 \mathrm{~h}$ at $33^{\circ} \mathrm{C}$. Basolateral medium and apical washings were collected separately, centrifuged, and supernatants were used for chemokine analysis. An optimal response to RV39 was observed at MOI of 1 and $24 \mathrm{~h}$ incubation period; these conditions were used for subsequent experiments.

For submerged cultures of 16HBE14o- cells, HEK293 cells with stable TLR3 expression, or vector control cells, bacteria were added to the medium at MOI of 1 or 10 and incubated for $8 \mathrm{~h}$. Medium along with unbound bacteria were removed and replaced with either RV39 (MOI of 1) or sham-infected medium and incubated for $1 \mathrm{~h}$ at $33^{\circ} \mathrm{C}$. The medium was then replaced, and the cells were incubated for an additional $24 \mathrm{~h}$. Medium was collected and centrifuged, and the supernatant was used for chemokine analysis. In selected experiments, cells were preincubated with neutralizing $\mathrm{Ab}$ against tumor necrosis factor (TNF)- $\alpha$ or TNF receptor I (TNFRI; R\&D Systems, Minneapolis, MN). In some experiments, RV infection was confirmed by reverse transcriptase-polymerase chain reaction (RT-PCR) using primer pairs based on the $5^{\prime}$ untranslated region which amplify both major and minor serotypes of RV. Primer pairs used were 5'TGGCAGATGAGGCTAGAAATACCCCAGTG3' (forward primer) and 5'CATCCCGCAATTGCTCGTTAC3' (reverse primer).

\section{Binding of RV39 to $16 \mathrm{HBE} 140$-cells}

16HBE14o- cells were grown in 12 wells until $80 \%$ confluency. Cells were shifted to serum- and antibiotic-free medium for at least $18 \mathrm{~h}$ and infected with $H$. influenzae at a MOI of 1 for $8 \mathrm{~h}$. Unbound bacteria were removed and replaced with fresh serum-free medium for another $16 \mathrm{~h}$. Medium was replaced with PBS-BSA (PBS containing 1\% BSA) or PBS-BSA containing $10 \mathrm{mM}$ EDTA for $1 \mathrm{~h}$ at $4^{\circ} \mathrm{C}$ and then incubated with prechilled PBS-BSA containing ${ }^{35}$ S-labeled RV or equal volumes of ${ }^{35} \mathrm{~S}$-labeled sham control in the presence or absence of $10 \mathrm{mM}$ EDTA for $1 \mathrm{~h}$ at $4^{\circ} \mathrm{C}$. Cells were washed with PBS-BSA or PBS-BSA containing $10 \mathrm{mM}$ EDTA to remove unbound RV. Cells were then lysed with $0.1 \%$ SDS, and 
radioactive counts of the lysates were determined. To obtain an estimate of specific binding of RV to epithelial cells, we subtracted the counts per minute (CPM) bound in the presence of EDTA from CPM bound in the absence of EDTA, as described previously (28). We then subtracted the CPM recovered from cells incubated with labeled sham control.

\section{Quantification of chemokines and cytokines}

The C-X-C chemokines IL-8, ENA-78, growth related oncogene (GRO)- $\alpha$, and the cytokine TNF- $\alpha$ were measured using Duoset ELISA development kits purchased from R\&D Systems.

Transfection of cells and measurement of IL-8 promoter activity

16HBE14o- cells grown in 6-well plates were transiently transfected with the $-162 /+44$ fragment of the human IL-8 promoter subcloned into a luciferase reporter (hIL-8/Luc, provided by Dr. Allan Brazier, University of Texas-Galveston; ref 29) and Renilla luciferase using Lipofectamine 2000 (Invitrogen, CA). The following day the cells were shifted to serum-free media and infected with $H$. influenzae at a MOI of 1 or 10 for $8 \mathrm{~h}$, followed by RV $\left(5 \times 10^{5}\right.$ TCID $\left._{50}\right)$ for $1 \mathrm{~h}$. Inoculum was replaced with fresh serum-free medium and incubated at $33^{\circ} \mathrm{C}$ for $18 \mathrm{~h}$, and the cells were harvested for analysis. Luciferase activity was measured using a luminometer. Changes in promoter activity were normalized for transfection efficiency by dividing luciferase light units by renilla luciferase light units. Results were then reported as fold increase over the empty vector/untreated control.

To determine the requirement of TLR3 for RV39-induced IL-8 expression, cells were transfected with TLR3 siRNA (from Santa Cruz Biotechnologies, Santa Cruz, CA, and Dharmacon, LaFayette, CO) along with hIL-8/Luc and Renilla luciferase. Cells transfected with nontargeting siRNA (Dharmacon) served as controls. To establish and optimize siRNA transfections, we used varying concentrations of specific and nontargeting siRNA, ranging from 5 to $60 \mathrm{pmol}$, and determined the expression of TLR3 by immunoblotting. We found that, at the $10 \mathrm{pmol}$ concentration, TLR3-specific but not nontargeting siRNA inhibited TLR3 protein expression. Hence, we used this concentration in subsequent experiments.

\section{Western blot analysis}

Transfected 16HBE140- cells were washed briefly in PBS, lysed in radio-immunoprecipitation assay (RIPA) buffer containing $50 \mathrm{mM}$ Tris $\mathrm{pH}$ 7.5, $150 \mathrm{mM} \mathrm{NaCl}, 1 \mathrm{mM}$ EDTA, 1\% Nonidet P-40, and $0.25 \%$ sodium deoxycholate containing complete protease inhibitors (Roche, Indianapolis, IN); homogenized by passing through a 28 gauge needle; and centrifuged. Supernatants were subjected to SDS-PAGE, proteins were transferred to nitrocellulose, and the membrane was probed with Ab to TLR3 (Santa Cruz Biotechnology). Bound $\mathrm{Ab}$ was detected by secondary $\mathrm{Ab}$ conjugated to horseradish peroxidase, and the signal was detected by chemiluminescence.

\section{Flow cytometry}

After relevant treatment, 16HBE140- cells were harvested using cell dissociating buffer (Invitrogen, Carlsbad, CA) and washed with PBS-BSA (PBS containing $0.5 \%$ BSA). Cells were washed with PBS-BSA, incubated with polyclonal antibody
(pAb) to TLR3 ( $5 \mu \mathrm{g} / \mathrm{ml}$, Santa Cruz Biotechnology), monoclonal antibody (mAb) to ICAM-1 $(1 \mu \mathrm{g} / \mathrm{ml}$, Serotec, Raleigh, $\mathrm{NC}$ ), or matched isotype IgG control for $1 \mathrm{~h}$ on ice. Cells were washed and incubated for $30 \mathrm{~min}$ on ice with the corresponding second $\mathrm{Ab}$ conjugated to Alexa Fluor 488 (5 $\mu \mathrm{g} / \mathrm{ml}$, Molecular Probes, Portland, OR). For intracellular staining, cells were permeabilized by incubating in PBS-BSA containing $2 \%$ paraformaldehyde and $0.1 \%$ saponin (30) for $30 \mathrm{~min}$ on ice; cells were then incubated with primary and secondary antibodies as described above. Cells were washed, suspended in PBS-BSA, and analyzed with a Becton Dickinson FACSCalibur using CellQuest software.

\section{Immunochemistry}

Primary airway epithelial cells grown at air/liquid interface were fixed in methanol at $-20^{\circ} \mathrm{C}$ after relevant treatment and blocked with normal donkey serum. Cells were incubated with appropriate dilutions of anti-TLR3 or ICAM-1 (R\&D systems), and the bound Ab was detected with anti-goat (for TLR3) or anti-mouse (for ICAM-1) IgG conjugated with Alexa Fluor-488. Cells were visualized by confocal microscopy using a Zeiss LSM 510 confocal microscope mounted on a Zeiss Axiovert 100M inverted microscope.

\section{Data analysis}

Statistical significance was assessed by ANOVA. Differences identified by ANOVA were pinpointed by the Tukey-Kramer test.

\section{RESULTS}

\section{RV39 infection stimulates C-X-C chemokine production from human airway epithelial cells}

Well-differentiated human primary airway epithelial cells were infected apically with RV39 (MOI of 1) and incubated for $24 \mathrm{~h}$. Washings of apical surface and medium from the basolateral chamber were collected for quantification of IL-8, ENA-78, and GRO- $\alpha$ proteins by ELISA. Cell cultures infected with equal volumes of HeLa cell extract (sham) served as controls. Under these conditions, RV39 significantly increased the basolateral secretion of all three chemokines compared with sham-treated controls (Fig. 1). There were no changes in the concentration of chemokines in the apical secretions (data not shown).

\section{H. influenzae increases RV39-stimulated C-X-C chemokine production from airway epithelial cells}

To examine the effect of bacterial infection on RV39 stimulated C-X-C chemokines, we initially determined the optimal dose of bacteria and incubation time. Well-differentiated airway epithelial cell cultures were infected with $H$. influenzae at MOI of 0.1 or 1 and 10 and incubated for 4,8 , or $24 \mathrm{~h}$. This was followed by RV39 infection for $24 \mathrm{~h}$. We then measured the release of IL-8 as well as lactose dehydrogenase (LDH), a marker of cell death, in the basolateral chamber. We also examined cultures for phenotypic evidence of cell 

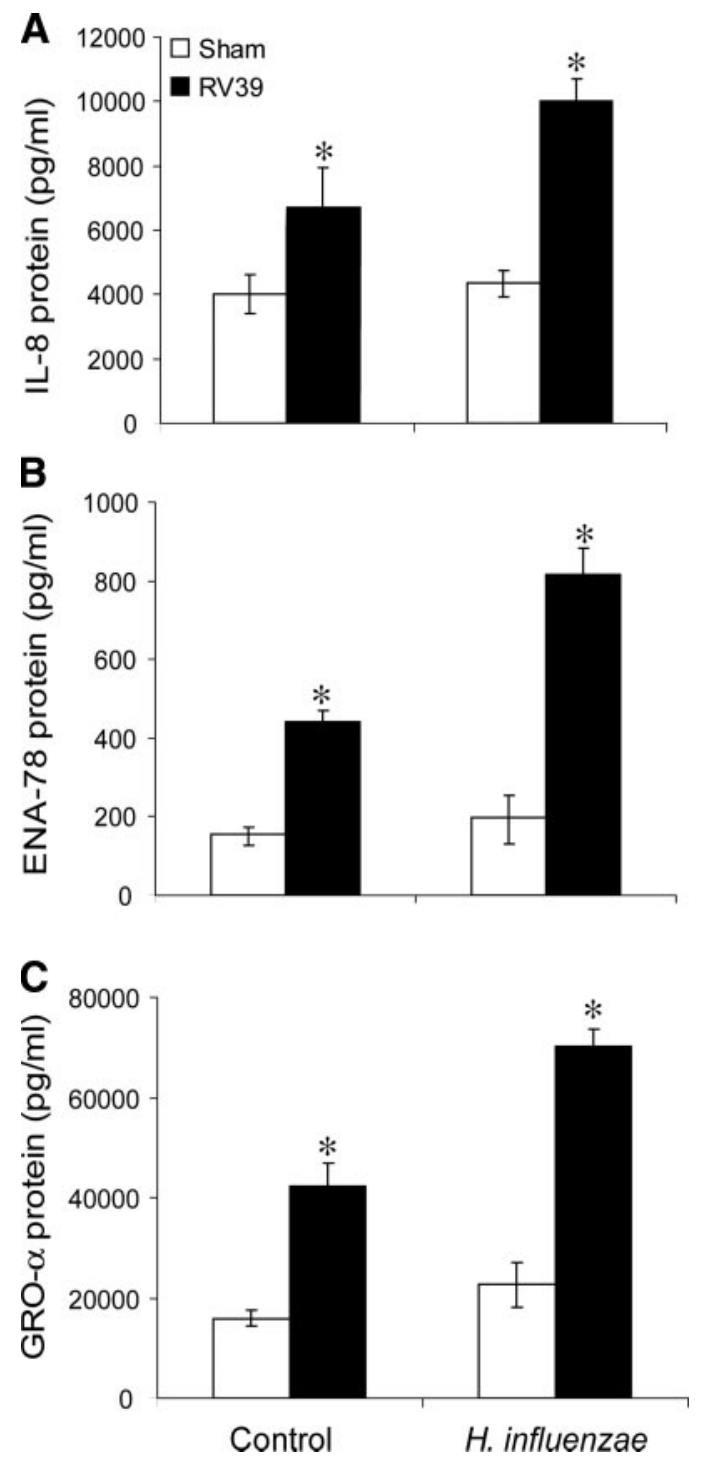

Figure 1. H. influenzae potentiates RV-39 induced IL-8 (A), ENA-78 (B), and GRO- $\alpha(C)$ expression in primary mucociliary-differentiated human tracheal epithelial cells. Primary human airway epithelial cells differentiated into mucociliary phenotype were infected with $H$. influenzae at MOI of 1 and incubated for $8 \mathrm{~h}$. Unbound bacteria were removed, and cells were infected with RV39 (MOI of 1 for $1 \mathrm{~h}$ ) apically. Cultures incubated with equal volumes of sham-infected HeLa cell extracts served as controls. Chemokine release in basolateral chamber was measured $24 \mathrm{~h}$ later by ELISA. Bars are mean \pm SE of 3 experiments; *different from sham infected, $P<0.05$, ANOVA.

damage. IL-8 release in the basolateral chamber was found to be maximum when cultures were incubated with $H$. influenzae at MOI of 1 for $8 \mathrm{~h}$ followed by RV39 for $24 \mathrm{~h}$ (data not shown). Based on the results of these initial studies, we used $H$. influezae at MOI of 1 and incubation time of $8 \mathrm{~h}$ for further studies. Increasing the incubation time of cultures with bacteria to $12 \mathrm{~h}$ before RV39 infection did not significantly increase IL-8 release. However, a further increase in incubation time to $24 \mathrm{~h}$ caused cytotoxic effects.

Cultures were infected apically with bacteria and incubated for $8 \mathrm{~h}$. Unbound bacteria were removed by washing the apical surface, and cells were then incubated with RV39 as before. Secreted IL-8, ENA-78, and GRO- $\alpha$ in the basolateral media were measured by ELISA. Cell cultures infected with both bacteria and RV39 secreted significantly more IL-8, ENA-78, and GRO- $\alpha$ than cells infected with RV39 or $H$. influenzae alone (Fig. 1). The observed stimulatory effect was additive.

Previously, we have shown that RV39 infection stimulates increased IL-8 expression in 16HBE14o- cells and that this expression of IL-8 is transcriptionally regulated (31). To examine whether $H$. influenzae potentiated RV39-induced IL-8 in 16HBE14o- cells, we infected these cells with bacteria for $8 \mathrm{~h}$ followed by RV39 for $24 \mathrm{~h}$ and measured IL-8 secretion in the supernatants. On average, RV39 alone stimulated a threefold increase of IL-8 compared with sham controls, whereas $H$. influenzae alone stimulated IL-8 twofold over mockinfected controls. However, bacteria and virus together increased IL-8 production from the 16HBE14o- cells in a synergistic (greater than additive) manner (8-fold over control, Fig. 2A). The observed effect was not unique to $H$. influenzae strain 12 , as we observed similar synergistic effects with three other nontypeable strains isolated from COPD patients (data not shown). However, heat-killed $H$. influenzae did not potentiate RVinduced IL-8 from airway epithelial cells, indicating that metabolically active bacteria are required. To examine if the IL-8 production is transcriptionally regulated, 16HBE14o- cells were transfected with hIL8/Luc and Renilla luciferase and infected with bacteria or/and virus as above. Luciferase activity was measured $24 \mathrm{~h}$ postinfection. RV39 and $H$. influenzae increased mean IL-8 promoter activity by three and fourfold, respectively, whereas bacteria and virus together increased promoter activity by eightfold (Fig. $2 B$ ). These results suggested that IL-8 expression in response to virus and bacteria is regulated at transcriptional level.

\section{H. influenzae increases RV39 binding to airway epithelial cells}

We hypothesized that the observed increase in RV39induced IL-8 expression in H. influenzae-infected cells is due to increased binding of RV39. To test this hypothesis, ${ }^{35}$ S-labeled RV39 or similarly prepared sham control was incubated at $4^{\circ} \mathrm{C}$ for $1 \mathrm{~h}$ with uninfected 16HBE14o- epithelial cells or cells infected with $H$. influenzae at MOI of 1 for $8 \mathrm{~h}$, and cell-associated radioactivity was determined. Pilot studies showed that binding of virus to airway epithelial cells was optimal at $1 \mathrm{~h}$ and that this did not change with $\mathrm{H}$. influenzae infection. Specific binding was determined by subtracting nonspecific CPM recovered from cells treated with sham control, as well as the background CPM recovered from RV-infected cells after EDTA treatment. Binding of RV39 to both infected and uninfected cells increased with greater concentrations of added virus and reached saturation (Fig. 3A). Binding of RV was 


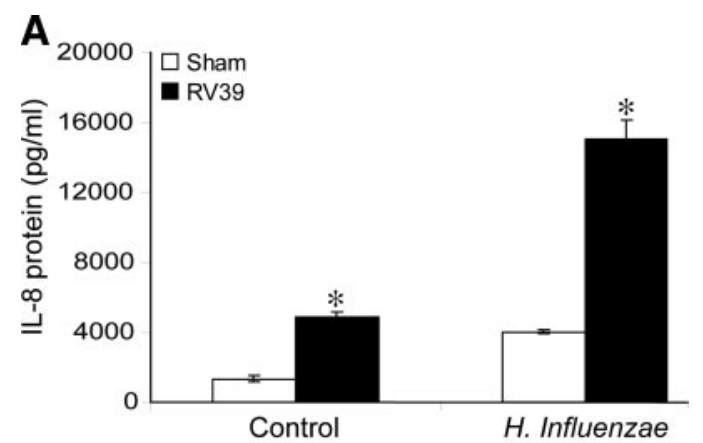

\section{B}

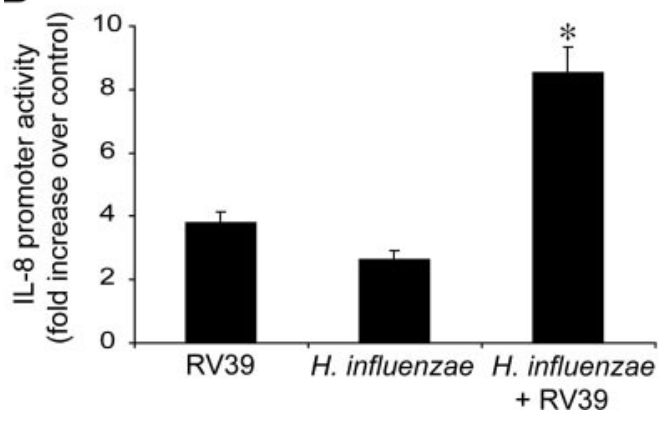

Figure 2. H. influenzae synergistically increases RV-39 stimulated IL-8 protein and IL-8 promoter activity in 16HBE14ocells. A) Epithelial cells grown to $80 \%$ confluence were serum starved overnight, infected with $H$. influenzae at MOI of 1 , and incubated for $8 \mathrm{~h}$. Unbound bacteria were removed, and cells were infected with RV39 at MOI of 1 for $1 \mathrm{~h}$. Medium was then replaced and cells further incubated for another $24 \mathrm{~h}$. IL-8 release in medium was determined by ELISA. Bars are mean \pm SE of 3 experiments; *different from uninfected, $P<$ 0.05 , ANOVA. B) For promoter assays, cells were transfected with hIL-8/Luc and Renilla $24 \mathrm{~h}$ before infection and luciferase activity determined by luminometer. Data were corrected for transfection efficiency and expressed as fold increase over uninfected control cells. Bars are mean \pm SE of 3 experiments; *different from infection with RV or H. influenzae alone, $P<0.05$, ANOVA.

substantially inhibited by neutralizing Ab to ICAM1 (Fig. 3B), indicating specific binding. Maximum RV39 binding was increased in cells infected with $H$. influenzae compared with uninfected cells, consistent with the notion that infection with $H$. influenzae increases RV39induced IL-8 expression by augmenting binding of RV to its epithelial cell receptor.

\section{H. influenzae increases expression of ICAM-1 and TLR3}

Next, we examined whether the increased binding of RV39 to $H$. influenzae-infected cells and the resultant increased production of C-X-C chemokines are associated with altered expression of ICAM-1 and TLR3. Binding of major subgroup RV to ICAM-1 is a prerequisite for airway epithelial cell IL-8 expression $(31,32)$. Although RV is a single-stranded RNA virus, during replication it makes double-stranded (ds)-RNA intermediates. TLR3, a type I transmembrane protein, me- diates immune responses to dsRNA (33). TLR3 is expressed in airway epithelial cells $(34,35)$, although the subcellular localization in differentiated polarized cells has not been resolved. Airway epithelial cells are activated by dsRNA (35-38), suggesting that TLR3 mediates RV-induced responses. However, the requirement of TLR3 for RV-induced responses has not been assessed.

16HBE14o- cells were infected with $H$. influenzae as described above, and the total and cell surface expression of ICAM-1 and TLR3 was determined by flow
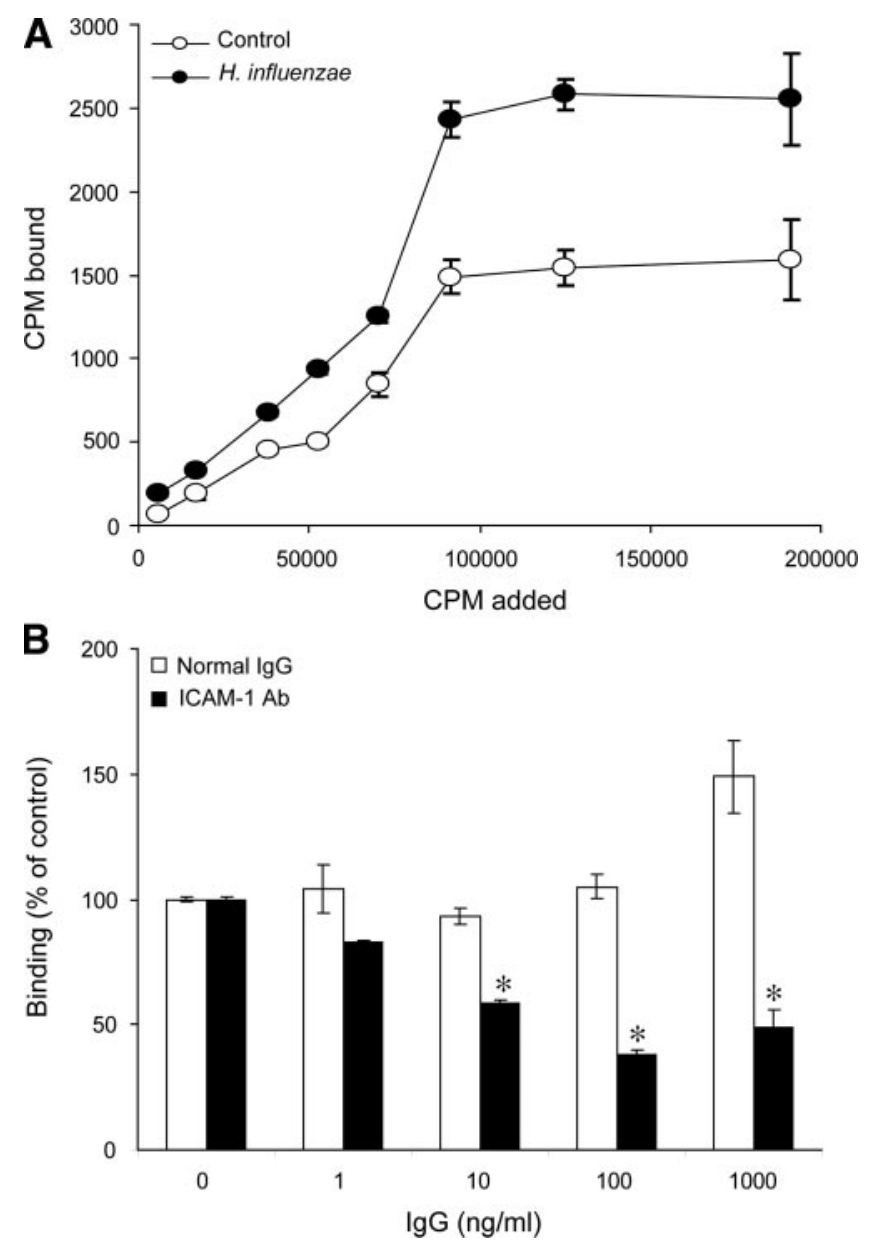

Figure 3. Binding of RV39 to $16 \mathrm{HBE} 14 \mathrm{o}-$ cells is increased in cells infected with $H$. influenzae. $16 \mathrm{HBE} 14 \mathrm{o}-$ cells grown to $80 \%$ confluence, serum-starved overnight and infected with $H$. influenzae as described in Fig. 2. A) Cells were then incubated with ${ }^{35}$ S-labeled RV39 or same volume ${ }^{35} \mathrm{~S}$ - labeled sham in the presence or absence of $10 \mathrm{mM}$ EDTA for $1 \mathrm{~h}$ at $4^{\circ} \mathrm{C}$. Unbound radiolabeled bacteria were removed, cells were lysed, and radioactivity was determined. Specific binding was calculated by subtracting radioactivity recovered from cells incubated with sham, as well as counts recovered in the presence of EDTA, from radioactivity obtained in the absence of EDTA. Three independent experiments were carried out in triplicate; results from a representative experiment are shown. B) Specificity of RV39 binding to 16HBE14o- cells infected with $H$. influenzae was determined by preincubating cells with normal IgG or mAb to ICAM-1 for $1 \mathrm{~h}$. ${ }^{35}$ S-labeled virus was added and binding determined. Bars are mean $\pm \mathrm{SE}$ of 3 experiments; *different from cultures uninfected with $H$. influenzae, $P<0.05$, ANOVA. 
cytometry. Cells infected with $H$. influenzae showed increased expression of both ICAM-1 and TLR3 (Fig. $4 A$ and $\boldsymbol{B})$. Whereas expression of ICAM-1 increased mainly on the cell surface, TLR3 expression increased mainly in the intracellular compartment (Fig. $4 C$ and $D$ ). Increased expression of ICAM-1 and TLR3 in well-differentiated human primary airway epithelial cell cultures on $H$. influenzae was confirmed by immunofluorescence. Similar to $16 \mathrm{HBE} 140-$ cells, $H$. influenzae infection increased expression of both ICAM- 1 and TLR3 in these cultures (Fig. $4 E$ and $F$ ). Confocal micrographs and Z-sections demonstrate that ICAM-1 expression is primarily confined to the apical surface, whereas TLR3 is localized primarily to the cell cytoplasm (Figs. $4 E-H$ ). These results suggest that $H$. influenzae increases RV39 binding to epithelial cells and potentiates RV39-stimulated chemokine expression by increasing the expression of the viral receptors ICAM-1 and TLR3.

\section{RV39-stimulated IL-8 expression is partially dependent on TLR3}

Next, we examined to what extent TLR3 contributes to RV39-stimulated IL-8 expression in airway epithelial cells taking two approaches. In the first approach, TLR3 expression in $16 \mathrm{HBE} 14 \mathrm{o}-$ cells was partially blocked using specific siRNA, and the effects on $H$. influenzae and RV39-induced IL-8 promoter activity were determined. Cells transfected with nontargeting siRNA served as controls in this set of experiments. TLR3 expression was assessed by immunoblotting. As observed earlier, infection of epithelial cells with $H$. influenzae increased TLR3 expression (Fig. 5A). Transfection of specific siRNA decreased the TLR3 expression in both uninfected and $H$. influenzae-infected cells. We then examined the effect of siRNA on transcription from the IL-8 promoter. Cells transfected with TLR3 siRNA (10 pmol) showed significantly decreased IL-8 promoter activity when stimulated by either RV39 alone or $H$. influenzae and RV39 (Fig. 5B). As would be expected, siRNA against TLR3 had no effect on H. influenzae-induced IL-8 expression. A second TLR3 siRNA showed similar effects (Fig. 5B). These results indicate that, in addition to ICAM-1, TLR3 is required for maximal RV39-induced IL-8 production.

In a second approach, HEK293 cells stably transfected with TLR3 or empty vector were infected with RV39. These cells express ICAM- 1 constitutively but do not express TLR3. HEK293 cells transfected with TLR3 expressed large amounts of TLR3 with no change in expression of ICAM-1 (Fig. $6 \boldsymbol{A}$ and $\boldsymbol{B}$ ). On average, cells expressing TLR3 produced 13-fold higher IL-8 levels on RV infection than untransfected HEK293 cells (Fig.
Figure 4. Increased expression ICAM-1 and TLR3 in H. influenzae-infected cells. 16HBE14ocells were infected with $H$. influenzae as described, immunostained with antibodies to ICAM-1 or TLR3, and analyzed by flow cytometry. $A$ and $B$ ) Representative histograms of fluorescence intensity of permeabilized $16 \mathrm{HBE} 14 \mathrm{o}-$ cells immunostained with ICAM-1 and TLR3 Ab, respectively. Similar results were obtained in 2 additional experiments. Intracellular expression of ICAM-1 $(C)$ and TLR3 (D) was calculated by subtracting the mean fluorescence intensity of nonpermeabilized cells from permeabilized cells. Expression of both ICAM-1 $(E)$ and TLR3 $(F)$ is increased in well-differentiated primary airway epithelial cells infected with $H$. influenzae compared with uninfected controls, as determined by immunofluorescent confocal microscopy. Z sections show cellular localization of ICAM-1 $(G)$ and TLR3 $(H)$. ICAM-1 is localized primarily to the cell surface, whereas TLR3 is primarily found in the cell cytoplasm.
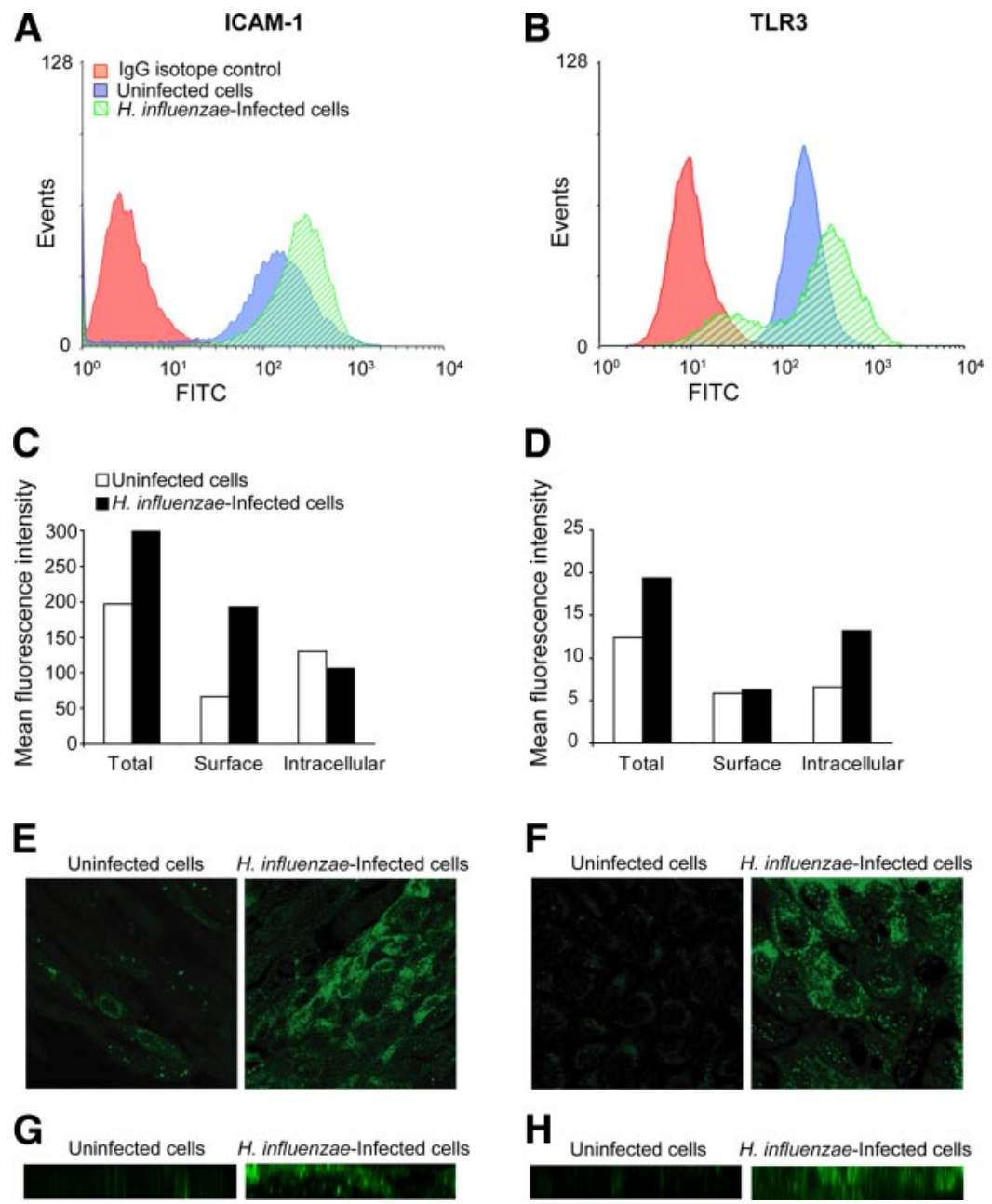


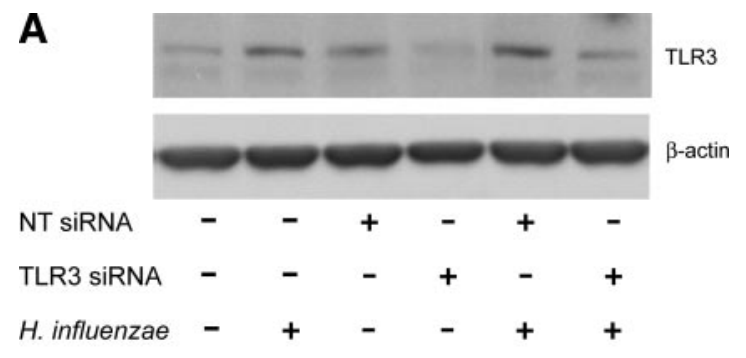

B
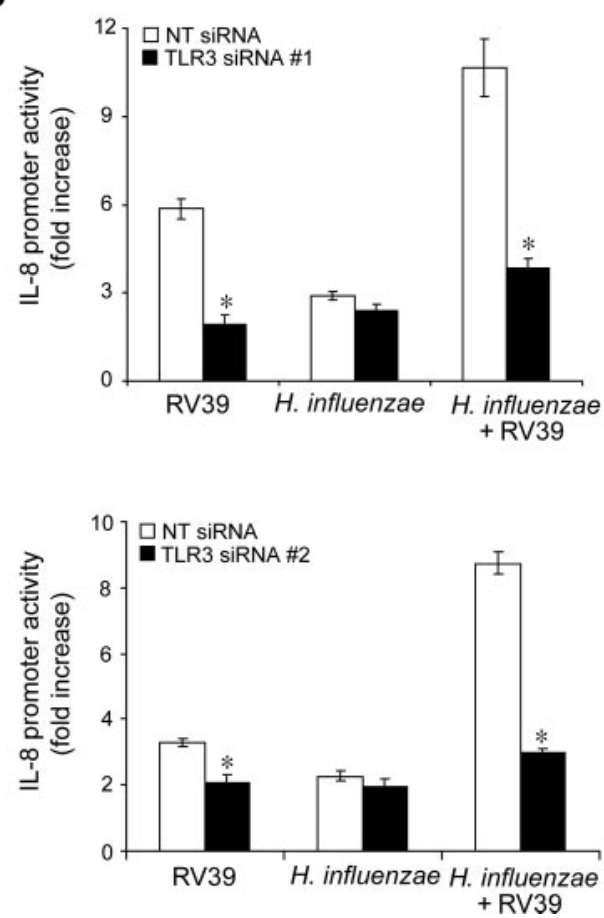

Figure 5. TLR3 is required for RV39-induced IL-8 expression. A) Infection with $H$. influenzae increased expression of TLR3 compared with uninfected controls. In contrast to nontargeting (NT) siRNA, TLR3 siRNA specifically decreased expression of TLR3 in uninfected and $H$. influenzae-infected cells. A representative immunoblot is shown. B) TLR3 siRNA decreased the RV39-stimulated IL-8 promoter activity. Upper panel) TLR3 siRNA1 (from Santa Cruz Biotechnology). Lower panel) TLR3 siRNA2 (from Dharmacon). Bars are mean $\pm \mathrm{SE}$ of 3 experiments; *different from nontargeting siRNA, $P<$ 0.05 , ANOVA. Cells transfected with nontarget RNA had no effect.

6C). RV39 RNA was detected by RT-PCR in both cell types $24 \mathrm{~h}$ postinfection (Fig. 6D), indicating that TLR3 is not required for $\mathrm{RV}$ infection but may be required for amplification of chemokine response. Taken together with the previous data, these data suggest that prior infection with $H$. influenzae increases RV39-induced IL-8 expression in part by increasing expression of TLR3.

\section{H. influenzae-induced TLR3 expression is mediated by TNF- $\alpha$}

Next, we wished to determine the mechanism by which $H$. influenzae induces TLR3 expression in airway epithe- lial cells. Instillation of bacterial lipopolysaccharides into rat lungs induces bronchial epithelial cell ICAM-1 expression in a TNF- $\alpha$-dependent manner (39). TNF- $\alpha$ increases airway epithelial cell ICAM-1 expression (40). We therefore hypothesized that TNF- $\alpha$, produced by epithelial cells in response to $H$. influenzae infection, is at least partially responsible for the observed increases in TLR3 expression and RV-induced IL-8 production in $H$. influenzae-infected cells. Initially, we established that 16HBE14o- cells secrete TNF- $\alpha$ within 5-15 min of infection with $H$. influenzae (Fig. 7A). To detect TNF- $\alpha$ in the cell culture supernatant, prior blocking of TNFR1 with neutralizing Ab was needed, apparently because TNF- $\alpha$ is rapidly bound to its receptor, which is highly abundant in $16 \mathrm{HBE} 140-$ cells. Next, we examined the effect of exogenous TNF- $\alpha$ on TLR3 expression. $16 \mathrm{HBE} 14 \mathrm{o}$ cells were incubated with $1 \mathrm{ng} / \mathrm{ml}$ of TNF- $\alpha$ for $24 \mathrm{~h}$, and total TLR3 expression was measured by flow cytometry. TNF- $\alpha$ increased the expression of TLR3, as assessed by mean fluorescence intensity, approximately twofold (Fig. $7 B$ and C). After establishing that TNF- $\alpha$ can in fact increase TLR3 expression, we examined whether neutralizing Ab can inhibit the augmented IL-8 production induced by RV39 in $H$. influenzae-infected cells. Cells were incubated with $H$. influenzae or TNF- $\alpha(1 \mathrm{ng} / \mathrm{ml})$ in the presence of $1 \mathrm{ng} / \mathrm{ml} \mathrm{TNF}-\alpha$ neutralizing $\mathrm{Ab}$ or normal IgG for $8 \mathrm{~h}$, and unbound bacteria were removed. Cells were then incubated with RV39 in presence of TNF- $\alpha$ neutralizing $\mathrm{Ab}$ for another $12 \mathrm{~h}$, and IL-8 released was quantified by ELISA (Fig. 7D). Previous work from our laboratory has shown that RV39-induced IL-8 responses do not require airway epithelial cell TNF- $\alpha$ production (31). In contrast, TNF- $\alpha$ neutralizing Ab partially inhibited IL-8 expression induced by the combination of $H$. influenzae and RV. Incubation with normal IgG had no effect. Together, these data suggest that $H$. influenzae increases expression of the TLR3 viral receptor via TNF- $\alpha$.

\section{DISCUSSION}

Nontypeable $H$. influenzae has been isolated from the airways of clinically stable COPD patients (1-3) and has also been associated with COPD exacerbations (4). Between 27 to $56 \%$ of COPD exacerbations are associated with respiratory viral infections, and RV is the most common virus isolated $(8-10)$. Respiratory viruses are more likely to be isolated in patients with a history of frequent COPD exacerbations (9), suggesting that patients with frequent exacerbations are more susceptible to viral infection (15). Nevertheless, little information exists regarding potential interactions between viruses and bacteria in the pathogenesis of COPD exacerbations. We hypothesized that $H$. influenzae infection increases expression of airway epithelial cell ICAM-1 and TLR3, leading to increased RV binding and exaggerated RV-induced chemokine responses. We found that infection with nontypeable $H$. influenzae increases 
Figure 6. HEK293 cells stably expressing TLR3 produce more IL-8 in response to RV39 infection. A) HEK293 cells stably transfected with TLR3 or empty vector express comparable amounts of ICAM-1. B) TLR3 expression is observed only in cells transfected with TLR3. C) HEK293 cells stably expressing TLR3 produced increased IL-8 in response to RV39 infection compared with HEK293 cells expressing empty vector. $D$ ) Cell lines demonstrated similar levels of RV39 RNA, as determined by RT-PCR. Bars are mean \pm SE of 3 experiments; *different from empty vector, $P<0.05$, ANOVA

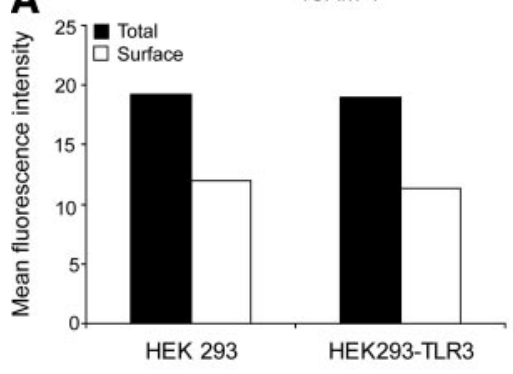

C

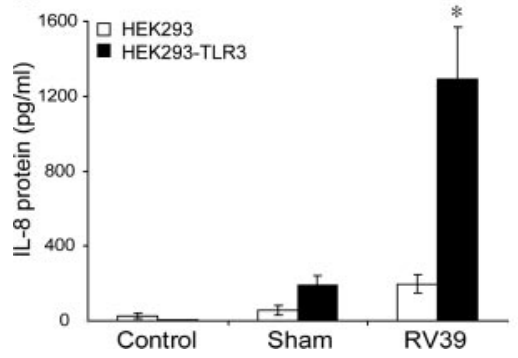

B

TLR3

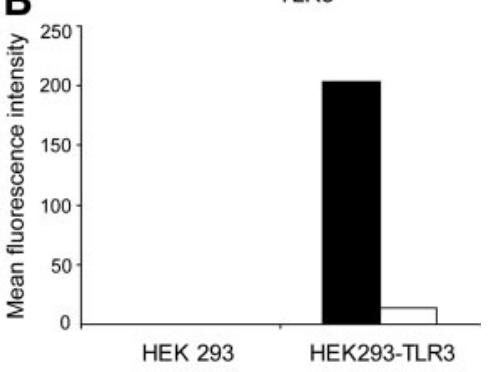

D

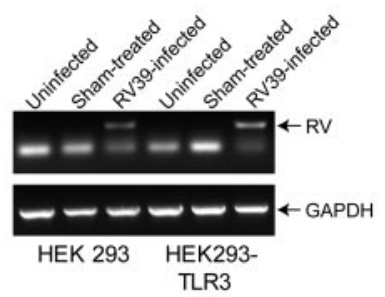

the expression of ICAM-1 and TLR3 in human airway epithelial cells differentiated into mucociliary phenotype, as well as $16 \mathrm{HBE} 140$ - cells growing as monolayers. We further showed that $H$. influenzae increases binding of RV39 to airway epithelial cells, leading to additive or synergistic increases the RV39-stimulated C-X-C chemokine expression. TNF- $\alpha$ was required for this response. Finally, we found that, in airway epithelial cells, TLR3 is required for maximal RV39-induced IL-8 expression.

Recently, we showed that RV39 infection of human airway epithelial cells is sufficient to activate phosphoti- dylinositol-3 kinase within minutes of infection, suggesting that ICAM-1 engagement is sufficient to activate signaling pathways leading to IL-8 expression (31). ICAM-1 is required for major subgroup RV-induced responses $(31,32)$. Cells differentiated into a psuedostratified mucociliary phenotype are harder to infect with major subgroup RV than cells differentiated into a squamous phenotype, which express higher levels of ICAM-1 (41). Conversely, erythromycin, which reduces expression of ICAM-1, inhibits RV binding to cells (42). Thus, alterations in receptor expression may modulate

Figure 7. TNF- $\alpha$ is sufficient to increase airway epithelial cell TLR3 expression, and is required for maximal RV39-induced IL-8 expression in $H$. influenzae preinfected cells. A) $H$. influenzae stimulates release of TNF- $\alpha$ from $16 \mathrm{HBE} 140-$ cells. B) Effect of exogenous TNF- $\alpha(1 \mathrm{ng} / \mathrm{ml}$ for $24 \mathrm{~h}$ ) on TLR3 expression, as measured by flow cytometry, a representative histogram. C) TNF- $\alpha$ increased expression of TLR3 by 2 -fold, and TLR-3 was localized primarily to the intracellular compartment. Data shown are from a representative experiment of 3 independent experiments. D) Effect of neutralizing $\mathrm{Ab}$ against TNF- $\alpha$ on RV39-induced IL-8 expression in $H$. influenzae infected or TNF- $\alpha$-treated cells. Previous work from our laboratory has shown that RV39-induced IL-8 responses do not require airway epithelial cell TNF- $\alpha$ production (31). In contrast, in cells preinfected with $H$. influenzae, treatment with TNF- $\alpha$ neutralizing $\mathrm{Ab}$, but not normal IgG, significantly decreased IL-8 expression. Bars are mean $\pm \mathrm{SE}$ of 3 experiments; *different from control IgG, $P<$ 0.05 , ANOVA.
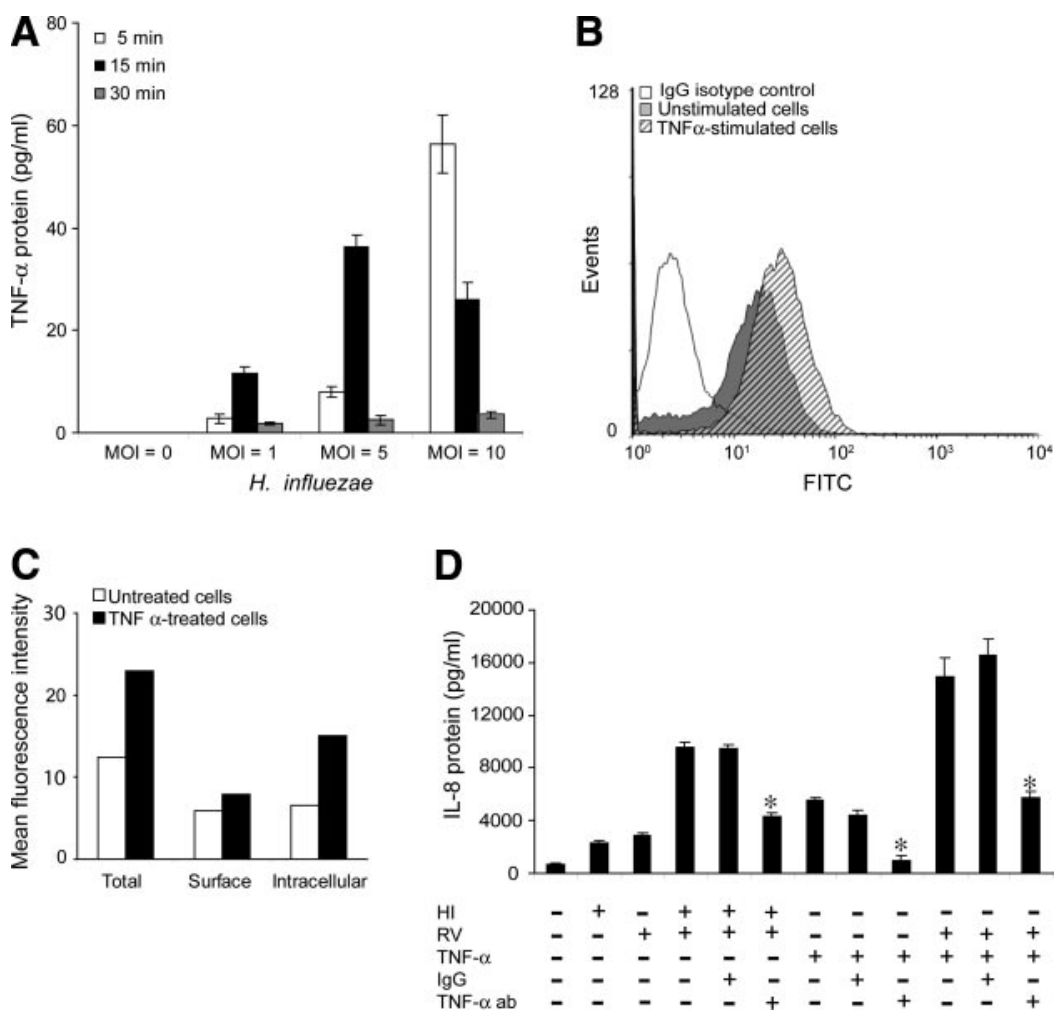
RV infectivity and responsiveness. In the present study, $H$. influenzae infection induced alterations of airway epithelial cell ICAM-1, which were associated with increases in RV binding and subsequent chemokine expression. Live but not heat-killed bacteria potentiated the RV-induced chemokine expression, indicating the requirement of metabolically active bacteria for the above processes. Together, these data provide a mechanism by which patients with frequent COPD may become more susceptible to viral infection (15). Furthermore, increased expression of $\operatorname{ELR}(+) \mathrm{C}$-X-C chemokines may stimulate COPD exacerbations by inducing an exaggerated neutrophilic inflammatory response.

In addition to ICAM-1 expression, infection of both primary and 16HBE14o- airway epithelial cells with $H$. influenzae increased expression of TLR3. H. influenzaestimulated TLR3 expression was mainly intracellular in location. TLR3 is an evolutionarily conserved pathogen recognition receptor that recognizes and binds dsRNA and activates transcription factors with a central role in innate immunity, NF-кB and IFN-regulatory factor 3 (43). It has recently been shown in BEAS-2B human bronchial epithelial cells that RV infection increases surface TLR3 expression (38). Although we did not systematically examine the effect of RV on TLR3 expression, RV appeared to increase the expression of this viral receptor, but perhaps not to the same degree as it does ICAM-1 (data not shown). Infection with other single-stranded RNA viruses, respiratory syncytial virus (RSV), and influenza A, increases TLR3 expression in A549 respiratory epithelial cells and BEAS-2B cells, respectively $(30,44)$. Poly (I:C), a synthetic analog of viral dsRNA, has recently been shown to increase TLR3 expression in primary human small airway epithelial cells (45).

Although the induction of TLR3 expression by RNA viruses or dsRNA may not be surprising, positive regulation of TLR3 due to bacterial infection of the respiratory epithelium has not been demonstrated previously. In BEAS-2B cells, expression of TLR3 was positively regulated by influenza A as well as dsRNA but not by other inflammatory mediators including bacterial LPS. Coculture of HT29 human colon adenocarcinoma cells with bacterial isolates from the rectal mucosa has recently been shown to increase TLR3 expression (46).

H. influenzae has previously been shown to stimulate respiratory epithelial cell ICAM-1 expression (17). This effect was not dependent on synthesis of lipooligosaccharide or on selected $H$. influenzae adhesins that promote high-affinity bacterial adherence. TNF- $\alpha$ increases airway epithelial cell ICAM-1 expression (40), and instillation of bacterial lipopolysaccharides into rat lungs induces bronchial epithelial cell ICAM-1 expression in a TNF- $\alpha$-dependent manner (39). In the present study, live $H$. influenzae stimulated secretion of TNF- $\alpha$ within the first 5-15 min of infection. We therefore hypothesized that $H$. influenzae-induced changes in RV receptor expression were mediated, at least in part, by TNF- $\alpha$. TNF- $\alpha$ increased the expression of TLR3 in airway epithelial cells approximately twofold. Furthermore, neutralizing Ab against TNF- $\alpha$ inhibited RV39stimulated IL-8 production in $H$. influenzae-infected cells. These data are consistent with the notion that airway epithelial production of TNF- $\alpha$ is required for $H$. influenzae-induced changes in RV receptor expression. RV39-induced IL-8 production in H. influenzae-preinfected cells is unlikely to be due to the direct effects of TNF- $\alpha$ on IL-8 transcription, since the effect of RV39 alone on IL-8 expression does not require TNF- $\alpha$ (31).

We found that TLR3-specific siRNA, which blocked both constitutive and $H$. influenzae-stimulated TLR3 expression in airway epithelial cells, also inhibited the RV-stimulated IL-8 production. Decreases in TLR3 expression and RV-stimulated IL-8 production were not observed when cells were transfected with nontargeting siRNA. Furthermore, HEK293 cells stably transfected with TLR3 produced high amounts of IL-8 in response to RV infection. Together, these findings suggest that TLR3 (specifically intracellular TLR3) is required for maximal IL-8 expression and sufficient, at least to some degree, for IL-8 expression in response to RV infection. Since RV dsRNA does not exist extracellularly, $H$. influenzae-induced up-regulation of intracellular TLR3 expression was likely responsible for the observed increase in chemokine expression. Intracellular TLR3 has previously been reported to be required for maximal IL-8 expression and NF- $\mathrm{B}$ transactivation to RSV and influenza A, respectively $(30,44)$. In contrast, it has recently been shown that neutralizing Ab to TLR3 increases chemokine expression stimulated by RV in BEAS-2B human bronchial epithelial cells (38). The discrepancy between this result and our own may be due to different method of blocking TLR3. Although neutralizing Ab can block surface-expressed TLR3, siRNA blocked global expression of TLR3 and hence may be more effective in inhibiting responses to dsRNA intermediates generated during the RV replication phase. The signaling pathway by which TLR3 engagement activates C-X-C chemokine production remains unclear.

In the aforementioned study, neutralizing $\mathrm{Ab}$ to TLR3 also increased RV replication (38). Similarly, TLR3-specific ligand inhibits hepatitis B virus replication (47), consistent with the notion that TLR3 mediates antiviral activity. TLR3-specific siRNA had no effect on RSV replication (44). Similarly, in the present study, HEK293 cells, which express ICAM-1 but not TLR3, showed similar levels of RV39 RNA by RT-PCR compared with cells overexpressing TLR3 suggesting TLR3 may not affect RV replication.

Finally, our observations of increased chemokine production in response to RV infection lie in contrast to data from Lopez-Souza et al. (41), who observed no significant increase in IL-8. The precise explanation for this discrepancy is unclear. We used a pure culture of passage 1 epithelial cells and did not deprive the cells of growth factors and hormones prior to RV infection. Our preliminary results suggest that such deprivation attenuates the IL-8 response to RV39 (U. Sajjan and M. 
Hershenson, unpublished data). We also used a different serotype of RV.

In summary, we have shown that infection of airway epithelial cells with $H$. influenzae increases expression of the RV receptors ICAM-1 and TLR3. In addition, we found that, like ICAM-1, TLR3 regulates IL-8 expression stimulated by major subgroup RV. Together, these data provide a mechanism for increased susceptibility to RV infection in COPD patients who are also infected with nontypeable $H$. influenzae. Indeed, studies in our laboratory indicate that TLR3 expression is increased in the small airways of at least some COPD patients (U. Sajjan, D. Arenberg, and M. Hershenson, unpublished data). Further investigation addressing potential interactions between viruses and bacteria in the pathogenesis of COPD exacerbations is therefore warranted. FJ

This work was supported by National Institutes of Health grants HL56399, HL81420, and HL82550 and the Cystic Fibrosis Foundation.

\section{REFERENCES}

1. Monso, E., Ruiz, J., Rosell, A., Manterola, J., Fiz, J., Morera, J., and Ausina, V. (1995) Bacterial infection in chronic obstructive pulmonary disease. A study of stable and exacerbated outpatients using the protected specimen brush. Am. J. Respir. Crit. Care Med. 152, 1316-1320

2. Soler, N., Ewig, S., Torres, A., Filella, X., Gonzalez, J., and Zaubet, A. (1999) Airway inflammation and bronchial microbial patterns in patients with stable chronic obstructive pulmonary disease. Eur. Respir. J. 14, 1015-1022

3. Murphy, T. F., Brauer, A. L., Schiffmacher, A. T., and Sethi, S. (2004) Persistent colonization by haemophilus influenzae in chronic obstructive pulmonary disease. Am. J. Respir. Crit. Care Med. 170, 266-272

4. Bandi, V., Apicella, M. A., Mason, E., Murphy, T. F., Siddiqi, A., Atmar, R. L., and Greenberg, S. B. (2001) Nontypeable Haemophilus influenzae in the lower respiratory tract of patients with chronic bronchitis. Am. J. Respir. Crit. Care Med. 164, 2114-2119

5. Sethi, S., Evans, N., Grant, B. J. B., and Murphy, T. F. (2002) New strains of bacteria and exacerbations of chronic obstructive pulmonary disease. N. Engl. J. Med. 347, 465-471

6. Eller, J., Ede, A., Schaberg, T., Niederman, M., Mauch, H., and Lode, H. (1998) Infective exacerbations of chronic bronchitis: relation between bacteriologic etiology and lung function. Chest 113, 1542-1548

7. Sethi, S. (2004) Bacteria in exacerbations of chronic obstructive pulmonary disease: phenomenon or epiphenomenon? Proc. Am. Thorac. Soc. 1, 109-114

8. Greenberg, S. B., Allen, M., Wilson, J., and Atmar, R. L. (2000) Respiratory viral infections in adults with and without chronic obstructive pulmonary disease. Am. J. Respir. Crit. Care Med. 162, $167-173$

9. Seemungal, T., Harper-Owen, R., Bhowmik, A., Moric, I., Sanderson, G., Message, S., Maccallum, P., Meade, T. W., Jeffries, D. J., Johnston, S. L., and Wedzicha, J. A. (2001) Respiratory viruses, symptoms, and inflammatory markers in acute exacerbations and stable chronic obstructive pulmonary disease. Am. J. Respir. Crit. Care Med. 164, 1618-1623

10. Rohde, G., Wiethege, A., Borg, I., Kauth, M., Bauer, T. T., Gillissen, A., Bufe, A., and Schultze-Werninghaus, G. (2003) Respiratory viruses in exacerbations of chronic obstructive pulmonary disease requiring hospitalisation: a case-control study. Thorax 58, 37-42

11. Halperin, S. A., Eggleston, P. A., Hendley, J. O., Suratt, P. M., Groschel, D. H., and Gwaltney, J. M. (1983) Pathogenesis of lower respiratory tract symptoms in experimental rhinovirus infection. Am. Rev. Respir. Dis. 128, 806-810
12. Gern, J. E., Galagan, D. M., Jarjour, N. N., Dick, E. C., and Busse, W. W. (1997) Detection of rhinovirus RNA in lower airway cells during experimentally induced infection. Am. J. Respir. Crit. Care Med. 155, 1159-1161

13. Papadopoulos, N. G., Bates, P. J., Bardin, P. G., Papi, A., Leir, S. H., Fraenkel, D. J., Meyer, J., Lackie, P. M., Sanderson, G., Holgate, S. T., and Johnston, S. L. (2000) Rhinoviruses infect the lower airways. J. Infect. Dis. 181, 1875-1884

14. Seemungal, T., Harper-Owen, R., Bhowmik, A., Jeffries, D., and Wedzicha, J. (2000) Detection of rhinovirus in induced sputum at exacerbation of chronic obstructive pulmonary disease. Eur. Respir. J. 16, 677-683

15. Wedzicha, J. A. (2004) Role of viruses in exacerbations of chronic obstructive pulmonary disease. Proc. Am. Thorac. Soc. 1, $115-120$

16. Bhowmik, A., Seemungal, T. A. R., Sapsford, R. J., and Wedzicha, J. A. (2000) Relation of sputum inflammatory markers to symptoms and lung function changes in COPD exacerbations. Thorax 55, 114-120

17. Qiu, Y., Zhu, J., Bandi, V., Atmar, R. L., Hattotuwa, K., Guntupalli, K. K., and Jeffery, P. K. (2003) Biopsy neutrophilia, neutrophil chemokine and receptor gene expression in severe exacerbations of chronic obstructive pulmonary disease. Am. J. Respir. Crit. Care Med. 168, 968-975

18. Gompertz, S., O’Brien, C., Bayley, D. L., Hill, S. L., and Stockley, R. A. (2001) Changes in bronchial inflammation during acute exacerbations of chronic bronchitis. Eur. Respir. J. 17, 1112-1119

19. Crooks, S., Bayley, D., Hill, S., and Stockley, R. (2000) Bronchial inflammation in acute bacterial exacerbations of chronic bronchitis: the role of leukotriene B4. Eur. Respir. J. 15, 274-280

20. Aaron, S. D., Angel, J. B., Lunau, M., Wright, K., Fex, C., Le Saux, N., and Dales, R. E. (2001) Granulocyte inflammatory markers and airway infection during acute exacerbation of chronic obstructive pulmonary disease. Am. J. Respir. Crit. Care Med. 163, 349-355

21. Di Stefano, A., Maestrelli, P., Roggeri, A., Turato, G., Calabro, S., Potena, A., Mapp, C. E., Ciaccia, A., Covacev, L., and Fabbri, L. M. (1994) Upregulation of adhesion molecules in the bronchial mucosa of subjects with chronic obstructive bronchitis Am. J. Respir. Crit. Care Med. 149, 803-810

22. Frick, A. G., Joseph, T. D., Pang, L., Rabe, A. M., St. Geme, J. W., III, and Look, D. C. (2000) Haemophilus influenzae stimulates ICAM-1 expression on respiratory epithelial cells. J. Immunol. 164, 4185-4196

23. Sajjan, U., Keshavjee, S., and Forstner, J. (2004) Responses of well-differentiated airway epithelial cell cultures from healthy donors and patients with cystic fibrosis to Burkholderia cenocepacia infection. Infect. Immun. 72, 4188-4199

24. Cozens, A. L., Yezzi, M. J., Kunzelmann, K., Ohrui, T., Chin, L., Eng, K., Finkbeiner, W. E., Widdicombe, J. H., and Gruenert, D. C. (1994) CFTR expression and chloride secretion in polarized immortal human bronchial epithelial cells. Am. J. Respir. Cell Mol. Biol. 10, 38-47

25. Winter, L. E., and Barenkamp, S. J. (2003) Human antibodies specific for the high-molecular-weight adhesion proteins of nontypeable haemophilus influenzae mediate opsonophagocytic activity. Infect. Immun. 71, 6884-6891

26. Papi, A., and Johnston, S. L. (1999) Rhinovirus infection induces expression of its own receptor intercellular adhesion molecule 1 (ICAM-1) via increased NF-kB-mediated transcription. J. Biol. Chem. 274, 9707-9720

27. Johnston, S. L., and Tyrrell, D. A. J. (1997) Rhinoviruses. In Diagnostic Procedures for Viral, Rickettsial, and Chlamydial Infection (Lennette, E. H., and Schmidt, N. J., eds) pp. 553-563, American Public Health Association, Washington D.C.

28. Bayer, N., Schober, D., Huttinger, M., Blaas, D., and Fuchs, R. (2001) Inhibition of clathrin-dependent endocytosis has multiple effects on human rhinovirus serotype 2 cell entry. J. Biol. Chem. 276, 3952-3962

29. Casola, A., Garofalo, R. P., Crawford, S. E., Estes, M. K. Mercurio, F., Crowe, S. E., and Brasier, A. R. (2002) Interleukin-8 gene regulation in intestinal epithelial cells infected with rotavirus: role of viral-induced IkappaB kinase activation. Virology 298, 8-19

30. Guillot, L., Le Goffic, R., Bloch, S., Escriou, N., Akira, S., Chignard, M., and Si-Tahar, M. (2005) Involvement of Toll-like receptor 3 in the immune response of lung epithelial cells to 
double-stranded RNA and influenza A virus. J. Biol. Chem. 280, $5571-5580$

31. Newcomb, D. C., Sajjan, U., Nanua, S., Jia, Y., Goldsmith, A. M., Bentley, J. K., and Hershenson, M. B. (2005) Phosphatidylinositol 3-kinase is required for rhinovirus-induced airway epithelial cell interleukin-8 expression. J. Biol. Chem. 280, 36952-36961

32. Kim, J., Sanders, S., Siekierski, E., Casolaro, V., and Proud, D. (2000) Role of NF-kappa B in cytokine production induced from human airway epithelial cells by rhinovirus infection. J. Immunol. 165, 3384-3392

33. Alexopoulou, L., Holt, A. C., Medzhitov, R., and Flavell, R. A. (2001) Recognition of double-stranded RNA and activation of NF-kappaB by Toll-like receptor 3. Nature 413, 732-738

34. Muir, A., Soong, G., Sokol, S., Reddy, B., Gomez, M. I., van Heeckeren, A., and Prince, A. (2004) Toll-Like receptors in normal and cystic fibrosis airway epithelial cells. Am. J. Respir. Cell Mol. Biol. 30, 777-783

35. Sha, Q., Truong-Tran, A. Q., Plitt, J. R., Beck, L. A., and Schleimer, R. P. (2004) Activation of airway epithelial cells by Toll-like receptor agonists. Am. J. Respir. Cell Mol. Biol. 31, 358-364

36. Gern, J. E., French, D. A., Grindle, K. A., Brockman-Schneider, R. A., Konno, S.-I., and Busse, W. W. (2003) Double-stranded RNA induces the synthesis of specific chemokines by bronchial epithelial cells. Am. J. Respir. Cell Mol. Biol. 28, 731-737

37. Duits, L. A., Nibbering, P. H., van Strijen, E., Vos, J. B., Mannesse-Lazeroms, S. P. G., van Sterkenburg, M. A., and Hiemstra, P. S. (2003) Rhinovirus increases human $\beta$-defensin-2 and -3 mRNA expression in cultured bronchial epithelial cells. FEMS Immunol. Med. Microbiol. 38, 59-64

38. Hewson, C. A., Jardine, A., Edwards, M. R., Laza-Stanca, V., and Johnston, S. L. (2005) Toll-Like receptor 3 is induced by and mediates antiviral activity against rhinovirus infection of human bronchial epithelial cells. J. Virol. 79, 12273-12279

39. Beck-Schimmer, B., Schimmer, R. C., Warner, R. L., Schmal, H., Nordblom, G., Flory, C. M., Lesch, M. E., Friedl, H. P., Schrier, D. J., and Ward, P. A. (1997) Expression of lung vascular and airway ICAM-1 after exposure to bacterial lipopolysaccharide. Am. J. Respir. Cell Mol. Biol. 17, 344-352
40. Bloemen, P. G., van den Tweel, M. C., Henricks, P. A., Engels, F., Wagenaar, S. S., Rutten, A. A., and Nijkamp, F. P. (1993) Expression and modulation of adhesion molecules on human bronchial epithelial cells. Am. J. Respir. Cell Mol. Biol. 9, 586-593

41. Lopez-Souza, N., Dolganov, G., Dubin, R., Sachs, L. A., Sassina, L., Sporer, H., Yagi, S., Schnurr, D., Boushey, H. A., and Widdicombe, J. H. (2004) Resistance of differentiated human airway epithelium to infection by rhinovirus. Am. J. Physiol. Lung Cell. Mol. Physiol. 286, L373-381

42. Suzuki, T., Yamaya, M., Sekizawa, K., Hosoda, M., Yamada, N., Ishizuka, S., Yoshino, A., Yasuda, H., Takahashi, H., Nishimura, H., and Sasaki, H. (2002) Erythromycin inhibits rhinovirus infection in cultured human tracheal epithelial cells. Am. J Respir. Crit. Care Med. 165, 1113-1118

43. Sato, S., Sugiyama, M., Yamamoto, M., Watanabe, Y., Kawai, T., Takeda, K., and Akira, S. (2003) Toll/IL-1 receptor domaincontaining adaptor inducing IFN-beta (TRIF) associates with TNF receptor-associated factor 6 and TANK-binding kinase 1 , and activates two distinct transcription factors, NF-kappa B and IFN-regulatory factor-3, in the Toll-like receptor signaling. J. Immunol. 171, 4304-4310

44. Rudd, B. D., Burstein, E., Duckett, C. S., Li, X., and Lukacs, N. W. (2005) Differential role for TLR3 in respiratory syncytial virus-induced chemokine expression. J. Virol. 79, 3350-3357

45. Ritter, M., Mennerich, D., Weith, A., and Seither, P. (2005) (2005) Characterization of Toll-like receptors in primary lung epithelial cells: strong impact of the TLR3 ligand poly(I:C) on the regulation of Toll-like receptors, adaptor proteins and inflammatory response. J. Inflamm. (Lond.) 2, 16-31

46. Furrie, E., Macfarlane, S., Thomson, G., and Macfarlane, G. T. (2005) Toll-like receptors-2, -3 and -4 expression patterns on human colon and their regulation by mucosal-associated bacteria. Immunology $115,565-574$

47. Isogawa, M., Robek, M. D., Furuichi, Y., and Chisari, F. V. (2005) Toll-like receptor signaling inhibits hepatitis B virus replication in vivo. J. Virol. 79, 7269-7272

Received for publication January 31, 2006. Accepted for publication May 15, 2006. 


\title{
H. influenzae potentiates airway epithelial cell responses to rhinovirus by increasing ICAM-1 and TLR3 expression
}

\author{
Umadevi S. Sajjan,* Yue Jia,* Dawn C. Newcomb, ${ }^{\dagger}$ J. Kelley Bentley, ${ }^{*}$ \\ Nicholas W. Lukacs, ${ }^{\dagger}$ John J. LiPuma, ${ }^{*}$ and Marc B. Hershenson ${ }^{*},+1$ \\ *Department of Pediatrics and Communicable Diseases, ${ }^{\dagger}$ Department of Molecular and Integrative \\ Physiology, and ${ }^{\ddagger}$ Department of Pathology, University of Michigan, Ann Arbor, Michigan, USA
}

To read the full text of this article, go to http://www.fasebj.org/cgi/doi/10.1096/fj.06-5806fje

\section{SPECIFIC AIM}

Chronic obstructive pulmonary disease (COPD) is a chronic, progressive disease with intermittent acute exacerbations associated with viral and/or bacterial infections. Nontypeable $H$. influenzae has been isolated from airways of clinically stable COPD patients, suggesting that it can cause chronic infection. Rhinovirus $(\mathrm{RV})$, a single-stranded RNA virus that is responsible for most of the common colds, is an important trigger of acute exacerbations in COPD patients. Respiratory viruses are more likely to be isolated in patients with a history of frequent COPD exacerbations, suggesting that patients with frequent exacerbations are more susceptible to viral infection. Nevertheless, little information exists regarding potential interactions between viruses and bacteria in the pathogenesis of COPD exacerbations. In the present study, we investigated the cooperative effects of $H$. influenzae and RV on $\operatorname{ELR}(+)$ C-X-C chemokine production from airway epithelial cells. We hypothesized that $H$. influenzae infection increases expression of airway epithelial cell intercellular adhesion molecule (ICAM)-1 and Toll-like receptor (TLR)-3, leading to increased RV binding and exaggerated RV-induced chemokine responses.

\section{PRINCIPAL FINDINGS}

\section{H. influenzae increases RV39-stimulated C-X-C} chemokine production from airway epithelial cells

Well-differentiated human primary airway epithelial cells grown at air-liquid interface were infected apically with RV39 at an multiplicity of infection (MOI) of 1 and incubated for $24 \mathrm{~h}$. Medium from the basolateral chamber was collected for quantification of interleukin (IL)-8, epithelialderived neutrophil attractant (ENA)-78, and growth-related oncogene (GRO)- $\alpha$ proteins by ELISA. Cultures infected with HeLa cell extract (sham) served as control. RV39 significantly increased the basolateral secretion of all three chemokines compared with controls (Fig. 1).
To examine the effect of bacterial infection on RV39-stimulated chemokines, well-differentiated airway epithelial cell cultures were infected with $H$. influenzae at MOI of 1 and incubated for $8 \mathrm{~h}$. Unbound bacteria were removed by washing of the apical surface, and cells were incubated with RV39 as before. Cell cultures infected with both bacteria and RV39 secreted significantly more IL-8, ENA-78, and GRO- $\alpha$ than cells infected with RV39 or H. influenzae alone (Fig. 1).

We found similar cooperative effects of $H$. influenzae and RV on transcription from the IL-8 promoter in 16HBE14o- human bronchial epithelial cells, suggesting that IL-8 expression in response to virus and bacteria is regulated at the transcriptional level.

\section{H. influenzae increases RV39 binding to airway} epithelial cells and expression of viral receptors ICAM-1 and TLR3

We hypothesized that the observed increase in RV39induced IL-8 expression in H. influenzae-infected cells is due to increased binding of RV39. To test this, ${ }^{35} \mathrm{~S}-$ labeled RV39 was incubated at $4^{\circ} \mathrm{C}$ for $1 \mathrm{~h}$ with uninfected 16HBE14o- cells or cells infected with $H$. influenzae at MOI of 1 for $8 \mathrm{~h}$, and cell-associated radioactivity was determined. Maximal RV39 binding was increased in cells infected with $H$. influenzae compared with uninfected cells. These data are consistent with the notion that infection with $H$. influenzae increases RV39-induced IL-8 expression by augmenting binding of RV to its epithelial cell receptor.

Next, we examined whether the increased binding of RV39 to $H$. influenzae-infected cells and the resultant increased production of C-X-C chemokines are associated with altered expression of ICAM-1 and TLR3. Binding of major subgroup RV to ICAM-1 is a prereq-

\footnotetext{
${ }^{1}$ Correspondence: University of Michigan, 1150 W. Medical Center Dr., Rm. 3570, MSRBII, Box 0688, Ann Arbor, MI 48109-0688, USA. E-mail: mhershen@umich.edu doi: 10.1096/fj.06-5806fje
} 

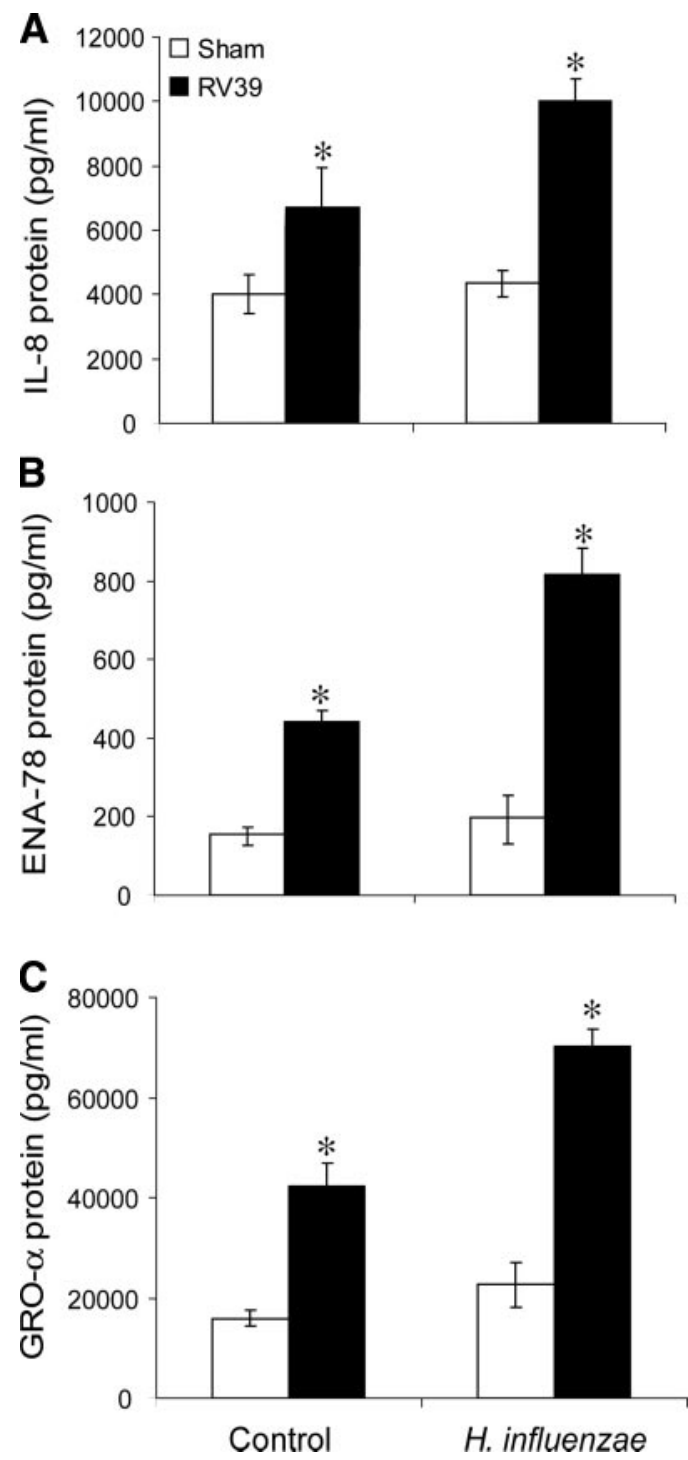

Figure 1. H. influenzae potentiates RV-39 induced IL-8 (A), ENA-78 (B), and GRO- $\alpha(C)$ expression in primary mucociliary-differentiated human tracheal epithelial cells. Primary human airway epithelial cells differentiated into mucociliary phenotype were infected with $H$. influenzae at MOI of 1 and incubated for $8 \mathrm{~h}$. Unbound bacteria were removed, and cells were infected with RV39 (MOI of 1 for $1 \mathrm{~h}$ ) apically. Cultures incubated with equal volumes of sham-infected HeLa cell extracts served as controls. Chemokine release in basolateral chamber was measured $24 \mathrm{~h}$ later by ELISA. Bars are mean $\pm \mathrm{SE}$ of 3 experiments; *different from sham infected, $P<0.05$, ANOVA.

uisite for airway epithelial cell IL-8 expression. TLR3 mediates immune responses to double-stranded (ds)RNA. Although RV is a single-stranded RNA virus, during replication it makes dsRNA intermediates. 16 HBE14o- cells were infected with $H$. influenzae as described above, and the total and cell surface expression of ICAM-1 and TLR3 was determined by flow cytometry. Cells infected with $H$. influenzae showed increased expression of both ICAM-1 and TLR3 (Fig. $\mathbf{2 A}$ and $\boldsymbol{B}$ ). Whereas expression of ICAM-1 increased mainly on the cell surface, TLR3 expression increased mainly in the intracellular compartment (Figs. $2 C$ and $D$ ). Similar to $16 \mathrm{HBE} 14 \mathrm{o}-$ cells, H. influenzae infection increased expression of both
ICAM-1 and TLR3 in differentiated human primary airway epithelial cell cultures. Confocal micrographs and Z-sections demonstrate that ICAM-1 expression is primarily confined to the apical surface, whereas TLR3 is localized primarily to the cell cytoplasm (Figs. $2 E-H$ ). These results suggest that $H$. influenzae increases RV39 binding to epithelial cells and potentiates RV39-stimulated chemokine expression by increasing expression of the viral receptors ICAM-1 and TLR3.

\section{RV39-stimulated IL-8 expression is partially dependent on TLR3; $H$. influenzae-induced TLR3 expression is mediated by TNF- $\alpha$}

Next, we examined to what extent TLR3 contributes to RV39-stimulated IL-8 expression in airway epithelial cells. In the first approach, TLR3 expression in 16HBE14o- cells was partially blocked using specific siRNA, and the effects on $H$. influenzae and RV39induced IL-8 promoter activity were determined. Cells transfected with two different preparations of TLR3 siRNA, but not nontargeting siRNA, showed significantly decreased IL-8 promoter activity when stimulated by either RV39 alone or H. influenzae and RV39. siRNA against TLR3 had no effect on $H$. influenzaeinduced IL-8 expression. These results indicate that TLR3 is required for maximal RV39-induced IL-8 production. In a second approach, human embryonic kidney (HEK)-293 cells stably transfected with TLR3 or empty vector were infected with RV39. These cells do not express TLR3 constitutively. On average, cells expressing TLR3 produced 13-fold higher IL-8 levels on RV infection than untransfected HEK293 cells. Together with the previous data, these data suggest that prior infection with $H$. influenzae increase RV39-induced IL-8 expression in part by increasing expression of TLR3.

We hypothesized that TNF- $\alpha$, produced by epithelial cells in response to $H$. influenzae infection, is at least partially responsible for the observed increases in TLR3 expression. 16HBE14o- cells secrete TNF- $\alpha$ within 5-15 min of infection with $H$. influenzae. TNF- $\alpha$ also increased the expression of TLR3 approximately fivefold. Incubation with TNF- $\alpha$ neutralizing antibody, but not normal IgG, caused dose-dependent inhibition of IL-8 expression induced by the combination of $H$. influenzae and RV. In contrast, previous work from our laboratory has shown that RV39-induced IL-8 responses do not require airway epithelial cell $\mathrm{TNF}-\alpha$ production. Together, these data suggest that $H$. influenzae increases expression of the TLR3 viral receptor via TNF- $\alpha$.

\section{CONCLUSIONS AND SIGNIFICANCE}

Little information exists regarding potential interactions between viruses and bacteria in the pathogenesis of COPD exacerbations. We hypothesized that $H$. influenzae infection increases expression of airway epithelial cell ICAM-1 and TLR3, leading to increased RV binding and exaggerated RV-induced chemokine responses. The requirement of TLR3, an evolutionarily conserved pathogen 
A

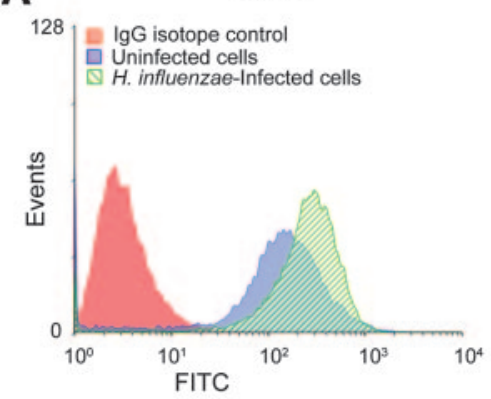

C

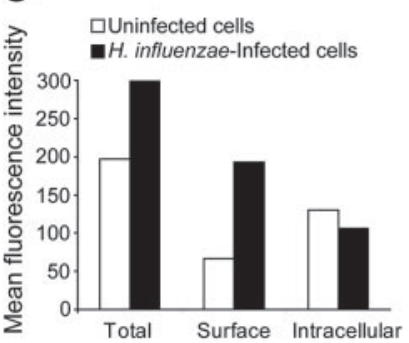

E
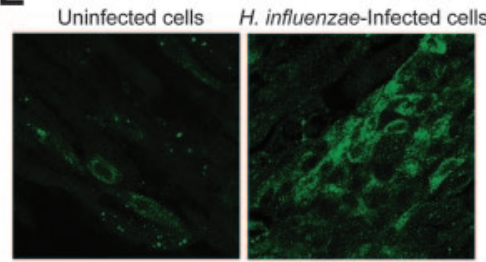

G

Uninfected cells $\quad H$. influenzae-Infected cells
B

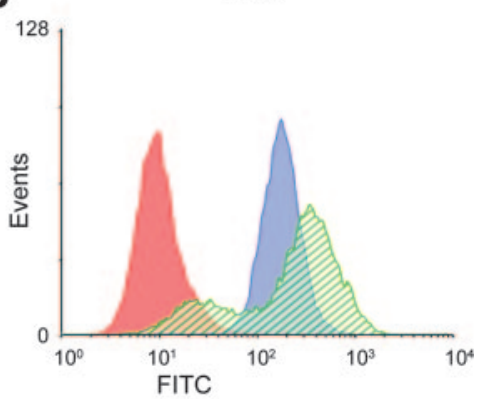

D

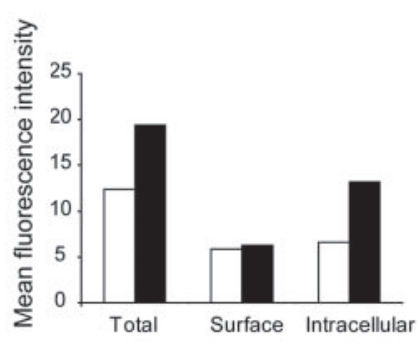

$\mathbf{F}$

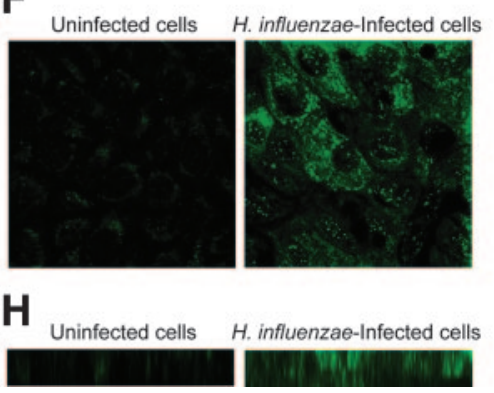

Figure 2. Increased expression ICAM-1 and TLR3 in H. influenzae-infected cells. 16HBE14ocells were infected with $H$. influenzae as described, immunostained with antibodies to ICAM-1 or TLR3, and analyzed by flow cytometry. $A$ and $B$ ) Representative histograms of fluorescence intensity of permeabilized 16HBE14o- cells immunostained with ICAM-1 and TLR3 Ab, respectively. Similar results were obtained in 2 additional experiments. Intracellular expression of ICAM-1 $(C)$ and TLR3 $(D)$ was calculated by subtracting the mean fluorescence intensity of nonpermeabilized cells from permeabilized cells. Expression of both ICAM-1 $(E)$ and TLR3 $(F)$ is increased in well-differentiated primary airway epithelial cells infected with $H$. influenzae compared with uninfected controls, as determined by immunofluorescent confocal microscopy. Z sections show cellular localization of ICAM-1 $(G)$ and TLR3 $(H)$. ICAM-1 is localized primarily to the cell surface, whereas TLR3 is primarily found in the cell cytoplasm. recognition receptor that recognizes and binds dsRNA, for RV-induced chemokine expression has not yet been tested.

We found that infection with nontypeable $H$. influenzae increases the expression of ICAM-1 and TLR3 in human airway epithelial cells differentiated into mucociliary phenotype, as well as $16 \mathrm{HBE} 140-$ cells growing as monolayers. We further showed that $H$. influenzae in-

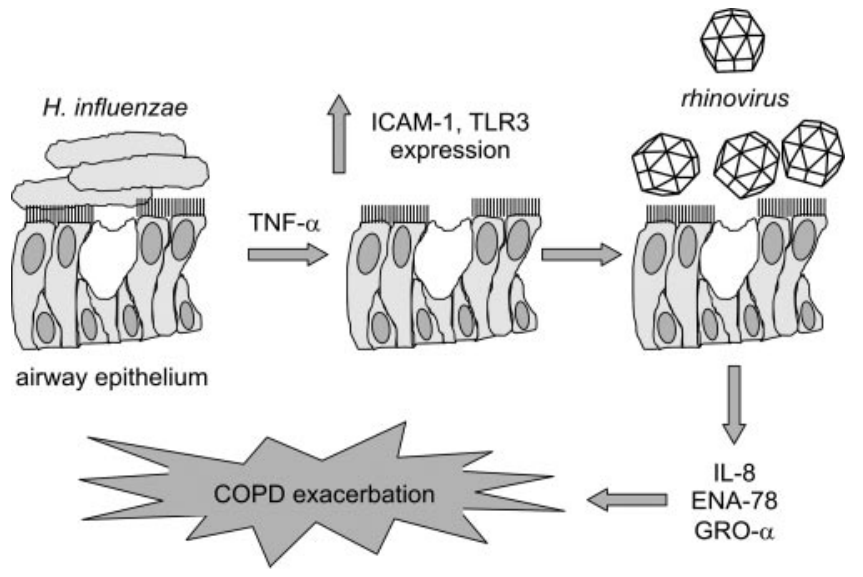

Figure 3. Summary schematic depicting a cellular mechanism by which prior infection with $H$. influenzae increases susceptibility of airway epithelial cells to RV infection, leading to increased chemokine expression and COPD exacerbation. creases binding of RV39 to airway epithelial cells, leading to cooperative increases the RV39-stimulated C-X-C chemokine expression. Together, these data provide a mechanism by which prior infection with nontypeable $H$. influenzae, as occurs in patients with COPD, may increase susceptibility to RV infection (Fig. 3). Although the induction of TLR3 expression by RNA viruses or dsRNA may not be surprising, positive regulation of TLR3 due to bacterial infection of the respiratory epithelium has not been demonstrated previously.

In addition, we found that TLR3-specific siRNA, which blocked both constitutive and $H$. influenzaestimulated TLR3 expression in airway epithelial cells, also inhibited the RV-stimulated IL-8 production. Furthermore, HEK293 cells stably transfected with TLR3 produced high amounts of IL- 8 in response to RV infection. Together, these findings show for the first time that TLR3 is required for maximal IL-8 expression and sufficient, at least to some degree, for IL-8 expression in response to $\mathrm{RV}$ infection.

Preliminary studies in our laboratory indicate that TLR3 expression is increased in the small airways of COPD patients (U. Sajjan, D. Arenberg, and M. Hershenson, unpublished data). Further investigation addressing potential interactions between viruses and bacteria in the pathogenesis of COPD exacerbations is therefore warranted.
F J 